\title{
Complex vascular anatomy is a predictor of silent cerebral ischemia after carotid artery stenting
}

\author{
Ahmet Guner $^{1}$ (D) • Macit Kalçık ${ }^{2} \cdot$ Ömer Çelik $^{1} \cdot$ Mehmet Ertürk $^{1}$ \\ Received: 15 September 2020 / Accepted: 4 October 2020 / Published online: 10 October 2020 \\ (C) Springer-Verlag GmbH Germany, part of Springer Nature 2020
}

To the Editor,

We have recently read with great interest the article by $\mathrm{Xu}$ et al. entitled "Risk factors for silent new ischemic cerebral lesions following carotid artery stenting" [1]. We appreciate the authors for their study describing the predictors of silent new ischemic cerebral lesions following carotid artery stenting. On the other hand, we believe that there are some major drawbacks that need to be addressed.

First of all, the presence of complex aortic arch anatomy may cause an increased risk of neurological complications [2-4]. Difficulty of cannulation that can be attributed to technical problems related with anatomical factors is associated with subclinical ischemic events. Recently, we have reported that a relationship between subclinical embolic events and the presence of type III aortic arch exists [3]. Moreover, Faggioli et al. previously indicated that proximal tortuosity increases the risk of both neurologic complications and technical failure [2]. However, in this study, the authors did not provide detailed information about the anatomical features of the carotid arteries as a predictor of silent ischemia.

Second, it was not surprising to detect a positive correlation between fluoroscopy time and subclinical embolism since increased procedure duration is a recognized risk factor for embolic events. Moreover, several authors have shown that fluoroscopy time is an independent predictor of stroke and silent cerebral infarction $[3,5]$. The readers may wonder whether the fluoroscopy time contributed the incidence of the silent new ischemic cerebral lesions following carotid artery stenting.

Ahmet Guner

ahmetguner488@gmail.com

1 Department of Cardiology, Mehmet Akif Ersoy Thoracic and Cardiovascular Surgery Training and Research Hospital, University of Health Sciences, Kucukcekmece, 34303 Istanbul, Turkey

2 Department of Cardiology, Faculty of Medicine, Hitit University, Çorum, Turkey
Funding No funding was received for this study.

\section{Compliance with ethical standards}

Conflict of interest The authors declare that they have no conflict of interest.

Ethical approval All procedures performed in the studies involving human participants were in accordance with the ethical standards of the institutional and/or national research committee and with the 1964 Helsinki Declaration and its later amendments or comparable ethical standards.

Informed consent Informed consent was obtained from all individual participants included in the study.

\section{References}

1. Xu X, Feng Y, Bai X, Ma Y, Wang Y, Chen Y, Yang B, Ling F, Zhang X, Jiao L (2020) Risk factors for silent new ischemic cerebral lesions following carotid artery stenting. Neuroradiology 62:11771184

2. Faggioli G, Ferri M, Gargiulo M, Freyrie A, Fratesi F, Manzoli L, Stella A (2007) Measurement and impact of proximal and distal tortuosity in carotid stenting procedures. J Vasc Surg 46:1119-1124

3. Celik O, Guner A, Kalcik M et al (2020) The predictive value of CHADS2 score for subclinical cerebral ischemia after carotid artery stenting (from the PREVENT-CAS trial). Catheter Cardiovasc Interv. https://doi.org/10.1002/CCD.29344

4. Liu J, Ke X, Lai Q (2020) Increased tortuosity of bilateral distal internal carotid artery is associated with white matter hyperintensities. Acta Radiol:028418512093238. https://doi.org/10. $1177 / 0284185120932386$. Online ahead of print

5. Naggara O, Touzé E, Beyssen B, Trinquart L, Chatellier G, Meder JF, Mas JL, EVA-3S Investigators (2011) Anatomical and technical factors associated with stroke or death during carotid angioplasty and stenting: results from the endarterectomy versus angioplasty in patients with symptomatic severe carotid stenosis (EVA-3S) trial and systematic review. Stroke 42:380-388

Publisher's note Springer Nature remains neutral with regard to jurisdictional claims in published maps and institutional affiliations. 